\title{
Mapping Forest Vertical Structure in Sogwang-ri Forest from Full-Waveform Lidar Point Clouds Using Deep Neural Network
}

\author{
Sung-Hwan Park ${ }^{1,2} \mathbb{D}$, Hyung-Sup Jung ${ }^{2,3}$, Sunmin Lee ${ }^{2,4, * \mathbb{C}}$ and Eun-Sook Kim ${ }^{5}$ \\ 1 Marine Disaster Research Center, Korea Institute of Ocean Science \& Technology, Busan 49111, Korea; \\ spark@kiost.ac.kr \\ 2 Department of Geoinformatics, University of Seoul, Seoul 02504, Korea; hsjung@uos.ac.kr \\ 3 Department of Smart Cities, University of Seoul, Seoul 02504, Korea \\ 4 Center for Environmental Assessment Monitoring, Korea Environment Institute (KEI), Sejong-si 30147, Korea \\ 5 Division of Forest Ecology, National Institute of Forest Science, Seoul 02455, Korea; drummer12@korea.kr \\ * Correspondence: smilee@kei.re.kr
}

Citation: Park, S.-H.; Jung, H.-S.; Lee, S.; Kim, E.-S. Mapping Forest Vertical Structure in Sogwang-ri Forest from Full-Waveform Lidar Point Clouds Using Deep Neural Network. Remote Sens. 2021, 13, 3736. https://doi.org/ $10.3390 / \mathrm{rs} 13183736$

Academic Editor: Lin Cao

Received: 10 August 2021

Accepted: 15 September 2021

Published: 17 September 2021

Publisher's Note: MDPI stays neutral with regard to jurisdictional claims in published maps and institutional affiliations.

Copyright: (c) 2021 by the authors. Licensee MDPI, Basel, Switzerland. This article is an open access article distributed under the terms and conditions of the Creative Commons Attribution (CC BY) license (https:/ / creativecommons.org/licenses/by/ $4.0 /)$.

\begin{abstract}
The role of forests is increasing because of rapid land use changes worldwide that have implications on ecosystems and the carbon cycle. Therefore, it is necessary to obtain accurate information about forests and build forest inventories. However, it is difficult to assess the internal structure of the forest through 2D remote sensing techniques and fieldwork. In this aspect, we proposed a method for estimating the vertical structure of forests based on full-waveform light detection and ranging (FW LiDAR) data in this study. Voxel-based tree point density maps were generated by estimating the number of canopy height points in each voxel grid from the raster digital terrain model (DTM) and canopy height points after pre-processing the LiDAR point clouds. We applied an unsupervised classification algorithm to the voxel-based tree point density maps and identified seven classes by profile pattern analysis for the forest vertical types. The classification accuracy was found to be $72.73 \%$ from the validation from 11 field investigation sites, which was additionally confirmed through comparative analysis with aerial images. Based on this pre-classification reference map, which is assumed to be ground truths, the deep neural network (DNN) model was finally applied to perform the final classification. As a result of accuracy assessment, it showed accuracy of $92.72 \%$ with a good performance. These results demonstrate the potential of vertical structure estimation for extensive forests using FW LiDAR data and that the distinction between one-storied and two-storied forests can be clearly represented. This technique is expected to contribute to efficient and effective management of forests based on accurate information derived from the proposed method.
\end{abstract}

Keywords: forest vertical structure; full-waveform LiDAR; deep neural network; deep learning; forest genetic resource reserve

\section{Introduction}

Vegetation provides the main structure of most habitat environments [1]. Forest structure and vegetation complexity can promote biodiversity and provide ecosystem services [2]. Therefore, estimates of forest structure are often used to assess the value and effectiveness of forest ecosystems [3]. The heterogeneity of forests is manifested in the diverse and complex growth patterns of plants [4]. Variation in the physical structure of forests creates a variety of microenvironments that supports many other organisms [5]. The number of microhabitats increases due to the complexity and heterogeneity of habitat type and the structural diversity of the forest [6]. Specifically, plants create a complex vegetation structure between the canopy and understory, creating more habitat niches that are used by birds, reptiles, and small mammals [7]. Forests containing tree species of different ages and sizes provide a suitable habitat for numerous plants and animals. In this context, it is suggested that observing the horizontal and vertical structure of forests helps understand the forest ecosystem. 
The structure provided by the forest forms the basis for the functioning of various other ecosystems. For example, vegetation prevents flooding by blocking and delaying direct rainfall through the canopy, ultimately reducing vulnerability to erosion [8]. In addition, the evaporative cooling effect of leaf layers in complex forests has a mitigating effect on climate [9]. It is also used as a basis for managing productivity [10] or terrestrial carbon stocks [11] that can be derived from vegetation structure variables in forests. Therefore, the measurement of vegetation structure is an essential component in managing and preserving biodiversity and ecosystem services. Accordingly, efforts are being made to establish a forest inventory that includes accurate forest structure information to institute appropriate forest policies in many countries. It is also important to accurately identify the tree characteristics for decision-making regarding conservation and protection policies related to forests.

While remote sensing imagery has been used to obtain information on forests in recent decades, field surveys have been essential to measure their vertical structure [12]. Fieldbased measurements using a clinometer and altimeter have the advantage of measuring the vertical structure of trees [13]. However, this technique is laborious, time-consuming, difficult to use in dense forests, and is not feasible for obtaining complete information for large forest areas. Remote sensing imagery, including optical aerial photography and satellite images, enables time-series forest mapping for areas where fieldwork cannot be conducted [14]. Forest vertical structures in a wide area have been classified mainly using superficial information with in situ data $[15,16]$. Nevertheless, it has the limitation of obtaining information only about the canopy layer and is unable to directly acquire data about the internal structure of the forest because of sensor characteristics that cannot penetrate through forest cover [17].

Although South Korea has $63.0 \%$ of its land covered by forests, it is less densely forested than many developed countries (trees per hectare) [18]. The Korean government conducts a national forest resource survey using the conventional methodology to evaluate the value of forest conservation. In addition, a digital database of forest maps and vegetation maps has been prepared and managed to offer spatial data types. In this database, the vertical structure of the forest is usually divided into four stories according to the height of the canopy: grass, shrub, understory, and canopy [19]. The information provided on the vertical structure of the forest based on periodic aerial and field surveys is unable to reflect the structural diversity of extensive forests. In addition, it is relatively difficult to assess the changes in forests as field surveys are more time-consuming compared to image-based data collection.

For the last 20 years, light detection and ranging (LiDAR) systems have been used in various fields including forestry for assessing vertical structure [20,21]. The LiDAR system is also applied to measure the vertical structure of the forest. Using laser pulses, it provides three-dimensional information about the forest in the form of cloud points, showing not only height but also structure between the canopy and the forest floor [22]. The LiDAR points reflected from the understory and shrub layers below the canopy layer can be used for estimating the forest vertical structure [23]. For example, if the LiDAR points converge only at a certain height, the area can be classified as a one-storied forest. Conversely, if they are vertically distributed between the top story of the forest and the ground, the area can be classified as a multi-storied forest. Various studies have used this concept to estimate and characterize forest structure using airborne LiDARs [23-25]. With technological advances, the structural patterns of the forest canopy are relatively well known; however, information about the sub-canopy or understory structure is still deficient [26].

The full-waveform (FW) LiDAR system accumulates return pulses to further enhance the advantages of LiDAR [27]. Theoretically, unlimited measurements per emission pulse are sampled at fixed time intervals to measure the overall profile of the entire return signal. Accordingly, the FW LiDAR obtains information for more points with a quasicontinuous recording of the reflected signal. Thus, FW LiDAR provides more detailed information about the forest structure [28], compared to the discrete return (DR) system [29] 
which can allow for a few returns to be recorded [30]; typically, it categorizes the returned signal into first to fourth returns. Numerous studies have compared FW and DR LiDAR systems $[29,31,32]$. Some information about the internal structure of forest that can be estimated only from FW LiDAR data [31]. In order to maximize the effectiveness of LiDAR, more research is needed to classify and map vertical structure types in forests.

In this respect, in order to overcome the uncertainty of data and map the spatial distribution, a number of deep learning techniques have recently been applied along with machine learning techniques $[33,34]$. In order to apply the models, research based on remote sensing data including spatial characteristics is mainly being conducted, and various types of images such as radar and optics are being used [35,36]. However, most general images contain only the surface information of the forest and accordingly, a study based on FW LiDAR data is required to estimate the internal property information of the forest $[15,23]$. Therefore, in this study, a deep neural network (DNN), one of well-known deep learning methods was adopted based on FW LiDAR data to estimate and classify the spatial distribution of the forest vertical structure.

This study aimed to classify the vertical structure in the Sogwang-ri Forest Genetic Resource Reserve in Uljin-gun, South Korea, using airborne FW LiDAR data. After preprocessing the FW LiDAR data, we enumerated the LiDAR-derived point cloud included in the voxel grid and generated a voxel-based tree point density map in a 3D raster format. Thereafter, we applied the unsupervised classification method of Iterative Self-Organizing Data Analysis (ISODATA) to reclassify the types of vertical structure; using profile pattern analysis, we identified seven classes of vertical structure. We validated the accuracy of the classification results by comparing them with forest vertical structure information derived from field investigations. Finally, based on the results of the pre-classified forest vertical structure, which is assumed as ground truths, DNN models were additionally applied for the final vertical structure classification.

\section{Materials and Methods}

The Korean government established the Sogwang-ri Forest Genetic Resource Reserve in October 2007 to preserve the natural forest and its ecosystems (Figure 1). It is a region that requires continuous management for ecological preservation as it is home to various rare plants such as Rhododendron micranthum, Cimicifuga heracleifolia var. bifida, Nakai or Loranthus tanakae Franch. and Sav. and endangered animals, including Naemorhedus caudatus (IUCN Red List VU), Felis bengalensis euptilura (IUCN Red List LC), Martes flavigula koreana (IUCN Red List LC), and Pteromys volans (IUCN Red List LC). With this background, 1610 ha was first designated as a forest genetic resource reserve area in 1982, which was subsequently expanded to $3705 \mathrm{ha}$, and efforts are being made to protect and foster forest resources and preserve forest biodiversity [37]. Moreover, since 2013, cases of pine tree mortality have been regularly reported in the area, highlighting the need for accurate information on changes in forest conditions [38].

The forests of the study area are composed of deciduous trees (55.1\%) as well as conifers $(42.3 \%)$. Approximately $50 \%$ of the study area lies at an altitude of $500-700 \mathrm{~m}$, while $2.1 \%$ and $5.3 \%$ of the area lie at an altitude of over $1000 \mathrm{~m}$ and under $400 \mathrm{~m}$, respectively; approximately $70 \%$ of the study area has a slope of more than 30 degrees. Field investigations to measure the vertical structure of the forest were performed by the Korea National Institute of Forest Science (NiFS) on 27 and 28 May 2019. Validation of the vertical structure classification results of this study was conducted through the field survey data from the in situ points; since this area is Forest Genetic Resource Reserve which is not allowed to be accessed arbitrarily, the sampling points are located along the promenade. This step was performed to assume this classification result as actual data in the deep learning modeling process (Figure $1 \mathrm{~b}$ ). 


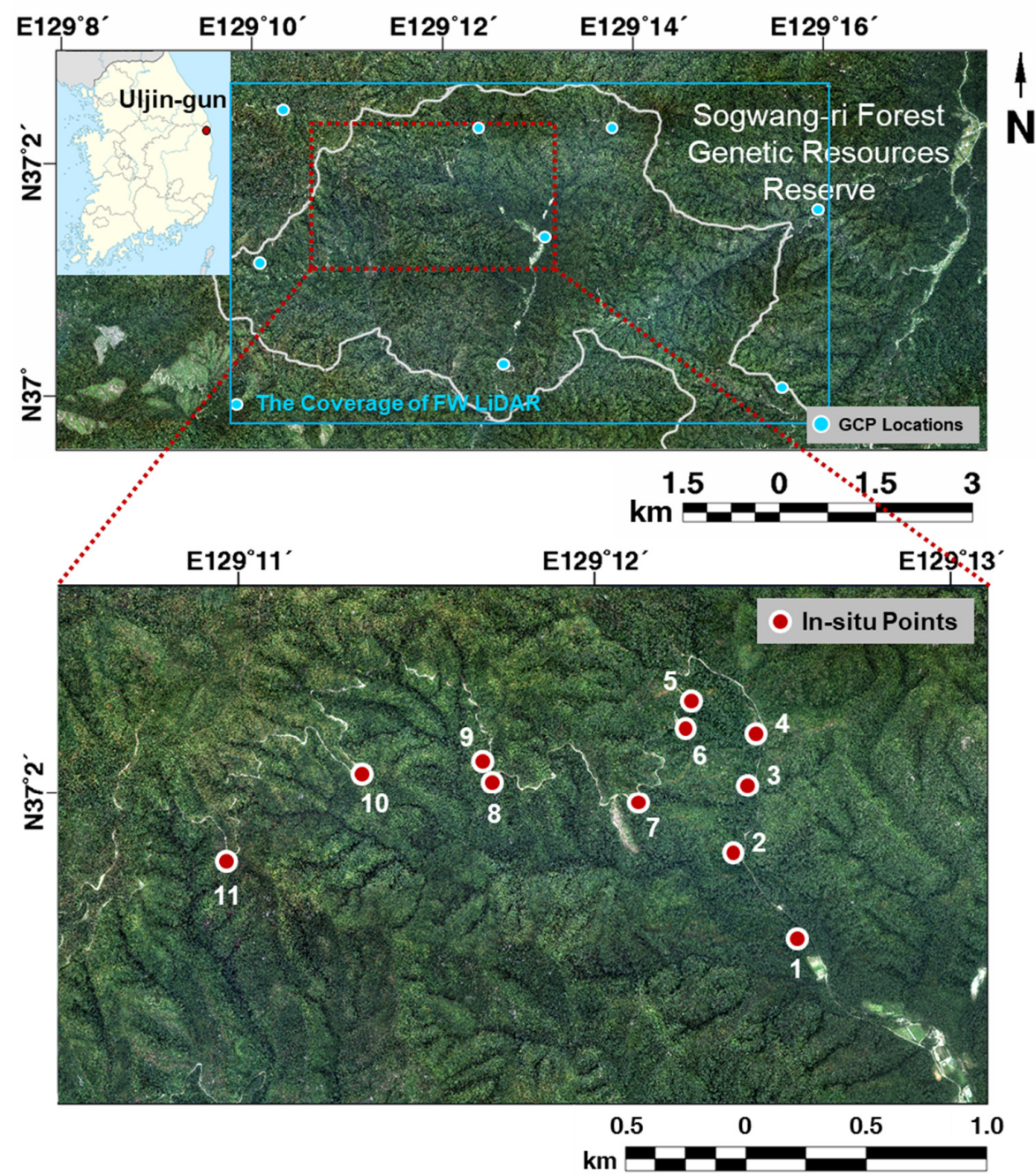

(a)

(b)

Figure 1. (a) The study area displaying the coverage of airborne LiDAR in Sogwang-ri Forest Genetic Resources Reserve and (b) field investigation sites. The source image is from an aerial photograph taken in 2016.

The vertical structure of the studied forest area was assessed using airborne FW LiDAR surveys on 14, 15, and 23 June, and 13 July 2017. A scanning system (Lite Mapper 6800; Integrated Geospatial Innovations, Kreuztal, Germany) mounted onto the Cessna 208 aircraft captured multiple returns of FW laser pulses over the study area terrain. A total of 70 paths with a $60 \%$ overlap were performed with a flight height of $1100 \mathrm{~m}$. A point density of approximately 16.5 points $/ \mathrm{m}^{2}$ was achieved, which is about two to four times higher than that in other studies using FW LiDAR [39]. In addition, we also conducted a ground control point (GCP) survey at nine points located within a $30 \mathrm{~km}$ radius of the study area to calibrate the geometric error of the $3 \mathrm{D}$ position acquired through the airborne LiDAR survey.

\section{Methodology}

The proposed method for classifying the forest vertical structure of the study area consisted of four steps (Figure 2): (A) pre-processing of LiDAR point clouds, (B) generation of voxel-based tree point density map by calculating the number of canopy height points in voxel grids, (C) pre-classification of forest vertical structure using unsupervised classification algorithms and profile pattern analysis, and (D) forest vertical structure classification using DNN based on the pre-classified forest vertical structure data. 


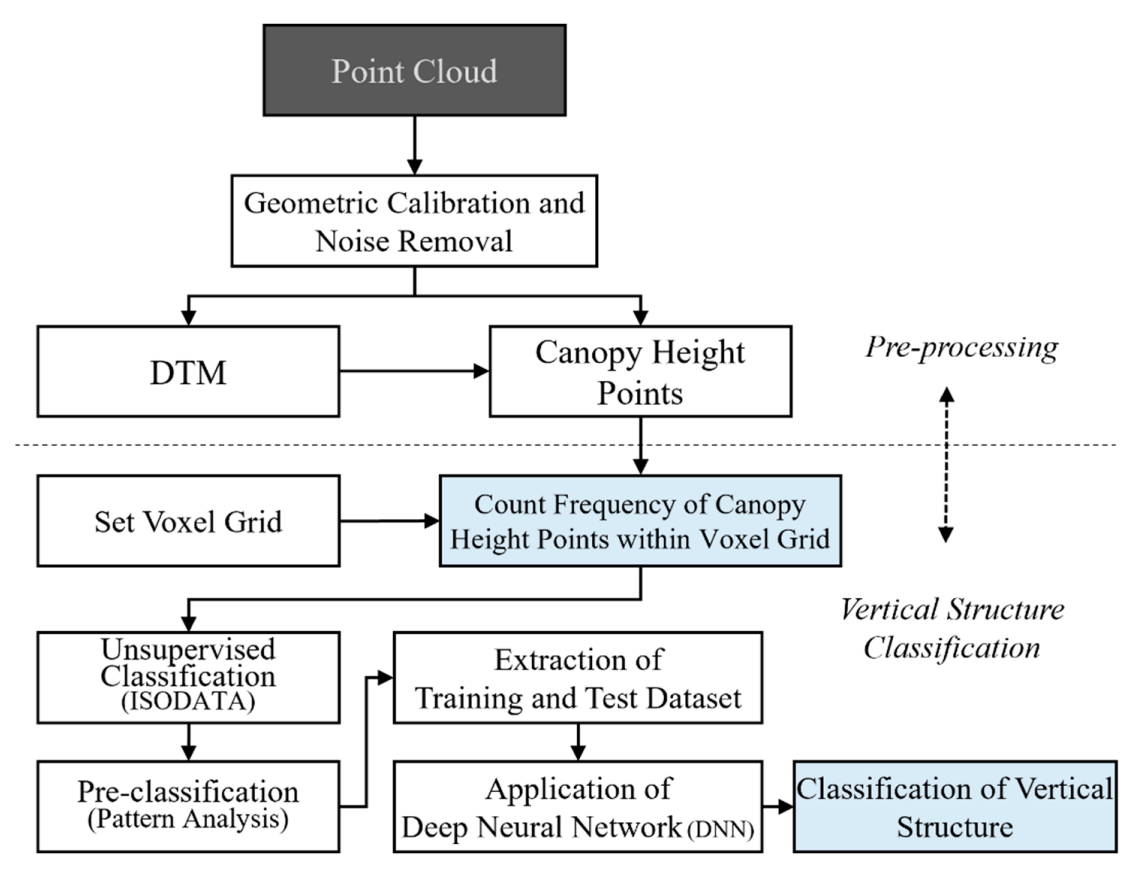

Figure 2. Data processing overall workflow.

\subsection{Pre-Processing of LiDAR Point Clouds}

In this step, we performed geometric calibration and noise removal of the raw LiDAR points. First, geometric calibration of the LiDAR point clouds was done using the Global Positioning System (GPS) and inertial navigation system (INS) of the aircraft and the nine GCPs placed in the study area (Figure 1). This process enabled the correction of the position error of 3D LiDAR point cloud caused by the attitude (roll, pitch, and yaw) of the aircraft. The GPS ground station was located on a reference point in a $30 \mathrm{~km}$ radius of the target area, and GPS data reception intervals were kept at $0.5 \mathrm{~s}(2 \mathrm{~Hz})$. GPS reception was also acquired and set to $0.5 \mathrm{~s}(2 \mathrm{~Hz})$, which was the same as the reception interval of the ground reference station. As a way of correcting the position error resulting from aircraft attitude error, it is acted upon in parallel with INS performance to produce the raw data of an accurate aerial LiDAR survey. The calculated correction amount of calibration for GCP was applied, and the height deviation of terrain for overlapping areas between routes was reviewed to correct the LiDAR point cloud.

Then, noise points (i.e., extremely high or low points outside the range of absolute elevations) were removed by filtering the LiDAR point clouds based on a triangulated irregular network (TIN) filtering algorithm [40]. Anomalously high points can be caused by atmospheric aerosols, clouds, birds, dust, electric wires, or low-flying aircraft, whereas low points can be caused by laser multipath or measuring instruments. The TIN filtering algorithm connects from below to the sub-randomly distributed points from the bottom of the TIN. The algorithm goes through an iterative operation that adds points to the TIN if the points are below a certain threshold. The initial threshold value of the iteration angle was set to $6^{\circ}$, and noise filtering was applied by decreasing the iteration angle when the edge length was less than $5 \mathrm{~m}$. TerraScan (Terrasolid Ltd., Helsinki, Finland) was used for LiDAR data acquired through pre-processing to remove noise from point clouds.

\subsection{Voxel-Based Tree Point Density Mapping}

The canopy height points were derived from pre-processed LiDAR point clouds. The DTM created from the ground-level LiDAR point clouds (X, Y, and Z values of the point cloud) was subtracted from the height value of $Z$ for all LiDAR point clouds; it was calculated by performing the topographic classification of vegetation and artificial features among the DSM data. The LiDAR point cloud with X, Y, and height values was generated and, then, converted to a voxel-based tree point density map. The voxel represented the 
frequency of normalized LiDAR point cloud points based on DTM, in their raster-based volumetric space. Each voxel has the value of the LiDAR point cloud ratio of voxels existing at a certain location. For this study, we constructed a voxel grid size similar to the criteria for the field survey. It provides strength to forest vertical structure analysis in that the frequency of the canopy height points can be estimated by height information of LiDAR point cloud [41]. Therefore, in this study, the forest vertical structure was estimated using a voxel-based tree point density map based on the frequency of canopy height points, which was determined according to the internal structure of the forest.

The number of voxels was defined as 509 in the horizontal direction and 310 in the vertical direction. Each voxel was $20 \times 20 \mathrm{~m}$ horizontally, and 0.5 to over $40 \mathrm{~m}$ height in the vertical direction was classified into 80 layers with $0.5 \mathrm{~m}$ height intervals. This was the defined spatial range of voxels as per the forest vertical structure measurement regulations of the National Institute of Forest Science, Korea [42].

The cell value of the voxel was determined by counting the frequency of the canopy height points within the horizontal and vertical ranges of the selected cell. As the mountainous study area and flight altitude produce a non-constant canopy height point density in all regions, the frequency was converted to a percentage over all canopy height points in each horizontal dimension. For example, a one-storied forest with tree height of $30 \mathrm{~m}$ displays a high value for the 20-30 m layer; non-forested areas show high values for $2-5 \mathrm{~m}$ and near-zero values for 20-30 m layers; a mixed area with shrub and canopy shows high values in both $20-30$ and $0-10$ m layers in the voxel grid. Voxel-based raster data was processed based on MATLAB (MathWorks, Inc., Natick, MA, USA) in this study.

\subsection{Pre-Classification of Forest Vertical Structure}

As a first classification step, we classified the forest vertical structure of the study area by analyzing the distribution of canopy height points in the voxel structure by heights using the ISODATA algorithm, which is a method that automatically classifies a target area based on statistical characteristics without training data. Unlike supervised classification, this algorithm generally requires only a minimal set of initial inputs. This algorithm performs numerical operations to identify natural groups, taking into account the properties of pixels [43]. The algorithm (a) iterates merging clusters if their separation distance in vertical feature space is below a user-specified threshold, and (b) splits a single cluster into two clusters when the statistics of the cluster exceed the acceptable standard deviation.

We used the following settings in the ISODATA algorithm to classify similar vertical structure groups from a voxel map: maximum iterations: 999, maximum number of classes: 255 , minimum members in a class: $0.01 \%$, maximum standard deviation: 2.58 , split separation value: 0 , and minimum distance between class means: 3.2 . We chose the maximum number of classes as 255 to subdivide the characteristics of the vertical structures as much as possible, since 255 vertical pattern classes would be regrouped by visual interpretation. This split-merge-assign procedure continued until the class assignment was $<2 \%$ between successive iterations. Unsupervised classification by using ISODATA was performed through ERDAS ER-mapper while other spatial data processing was performed through ArcMap 10.7 (ESRI, Redlands, CA, USA).

However, since the unsupervised classification method uses only mathematical characteristics, we conducted an additional process to specify the definition of each class after completion of the unsupervised classification. For this, we executed a reclassification process based on similar vertical structure characteristics since the number of classes was too large for grouping the vertical structure types in our study area. Therefore, we applied profile pattern analysis by visually analyzing the forest vertical structure in terms of seven classes with similar characteristics. Profile pattern analysis is based on specific classification criteria for integrating multiple classes into one by visual interpretation. Here, each class was classified into (1) a one-storied or multi-storied forest according to the frequency distribution of the voxel, and (2) appropriate strata according to the height corresponding to the maximum frequency. For example, a class with one peak point is classified as a one-storied 
forest, and if the number of peak points is greater than two, the class is classified as a multi-storied forest. The peak point at a height of $5 \mathrm{~m}$ and a point with peak-frequency at $20 \mathrm{~m}$ height are both one-storied forests but belong to different classes. Pre-classification result with seven forest vertical pattern classes was used for reference data for applying deep learning model in the next step.

\subsection{Application of Deep Neural Network}

Artificial neural network (ANN) is one of the widely used machine learning algorithms, which has the basic structure of a neural network for deep learning. ANN is a simple feedforward network consisting of an input layer, a hidden layer and an output layer. For the learning process of updating the weight of the connection between each layer, an error backpropagation algorithm is used, which is generally known to be effective [44]. The error backpropagation method uses mean squared error (MSE) as a cost function, which minimizes the MSE of the output and target value; it uses stochastic gradient descent (SGD) to minimize the cost. Through this learning process, it iteratively predicts the entire data until a preset parameter is satisfied.

DNN is one of the deep learning methodologies with many hidden layers, and it predicts and classifies in the same way as ANN in a feedforward method. As the number of layers increases, the network becomes more complex and the layer that best fits the data can be created. In this study, DNN was applied based on the pre-classification of forest vertical structure. In order to train each model, 1500 pixels for each class were randomly selected from the pre-classification result, and a total of 10,500 training pixel were selected. Among them, the training data ratio for each class was set to 0.8 ; the training and test sets were set to 8407 and 2093, respectively.

In the case of the DNN in this study, the architecture was constructed using [800, 800, 480, 240, 80, 240, 480, 800, 800] sequential hidden nodes (Figure 3). The rectified linear unit (ReLU) and Adam were selected as the activation function and optimizer, respectively; the learning rate was set to 0.001 . The maximum epochs and batch sizes for all models were set to 3000 and 70, respectively. Finally, precision-recall curve to multi-class was used for the model evaluation.

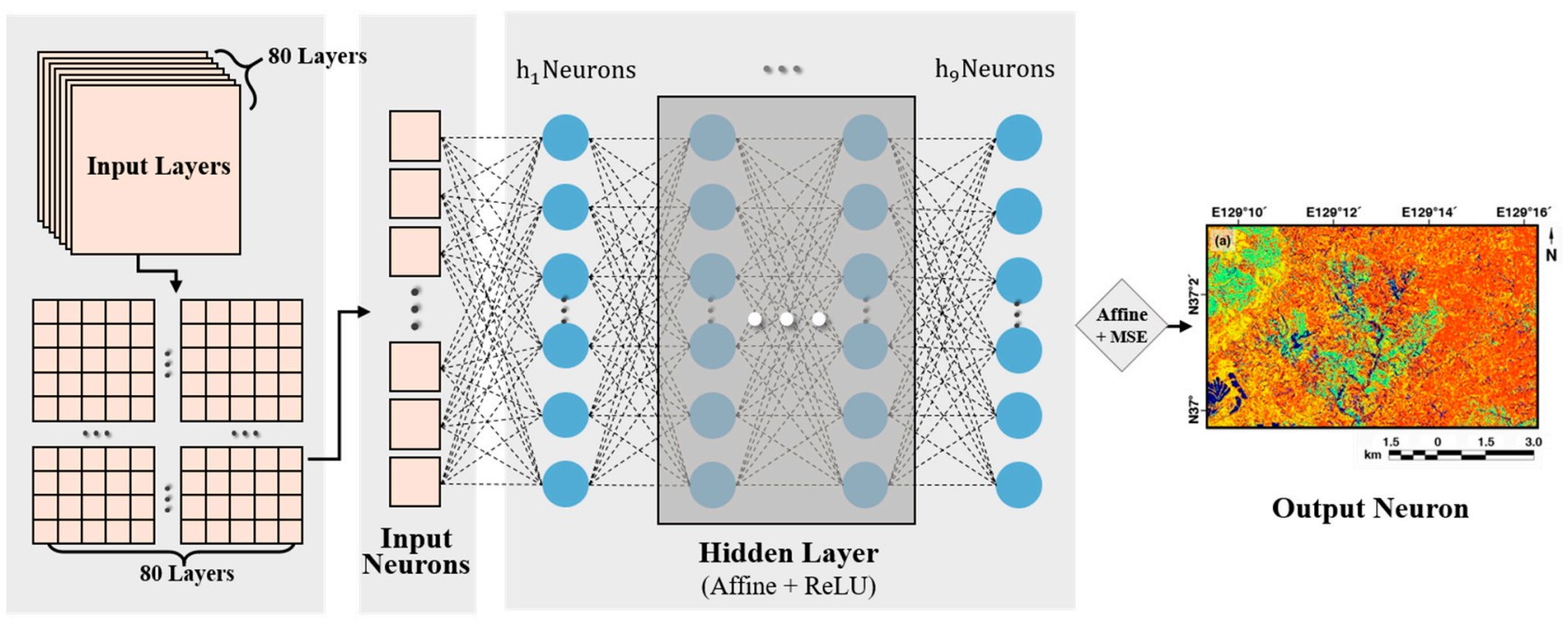

Figure 3. Deep neural network (DNN) architecture proposed in this study.

\section{Results and Discussion}

\subsection{Pre-Processing}

The three-dimensional coordinates of LiDAR points obtained from aerial surveys were corrected to have a root mean square error of $<25 \mathrm{~cm}$ using a pre-processing step of geometric correction. The overall average of the point densities generated after removing the noise in the LiDAR raw data was 16.56 points $/ \mathrm{m}^{2}$. Considering the example of 
point no. 3 (see Figure 1b), Figure 4 shows the raster-based DTM, digital surface model (DSM), and raster canopy height map (CHM) generated from the LiDAR points after preprocessing. The aerial image taken in 2016 (Figure 4a) exhibited a relatively similar form as the forest area represented by DSM (Figure 4c) and CHM (Figure 4d), even though there was a difference of approximately one year from when the aerial survey was conducted. However, the aerial image did not match perfectly with the aerial survey results due to the displacement error of the aerial image due to geometrical errors caused by photographing angle. Therefore, DSM and CHM could represent information about individual trees and forest distribution, whereas CHM generated by the difference between DSM and DTM visually showed forest height and distribution. Site observations revealed that trees located on the west of the road (Figure $4 \mathrm{a}$ ) consisted of pine trees with $\mathrm{DBH}>30 \mathrm{~cm}$ and height $\sim 30 \mathrm{~m}$, whereas the forest east of the road consisted of a mixture of pine trees and deciduous trees of various heights, which was similar to the representation in the raster CHM (Figure $4 \mathrm{~d}$ ). While this raster CHM could assess tree height and distribution of forest stands, information about the points returned from treetops may have been lost during DSM interpolation, thus making it difficult to obtain internal information about the forest.
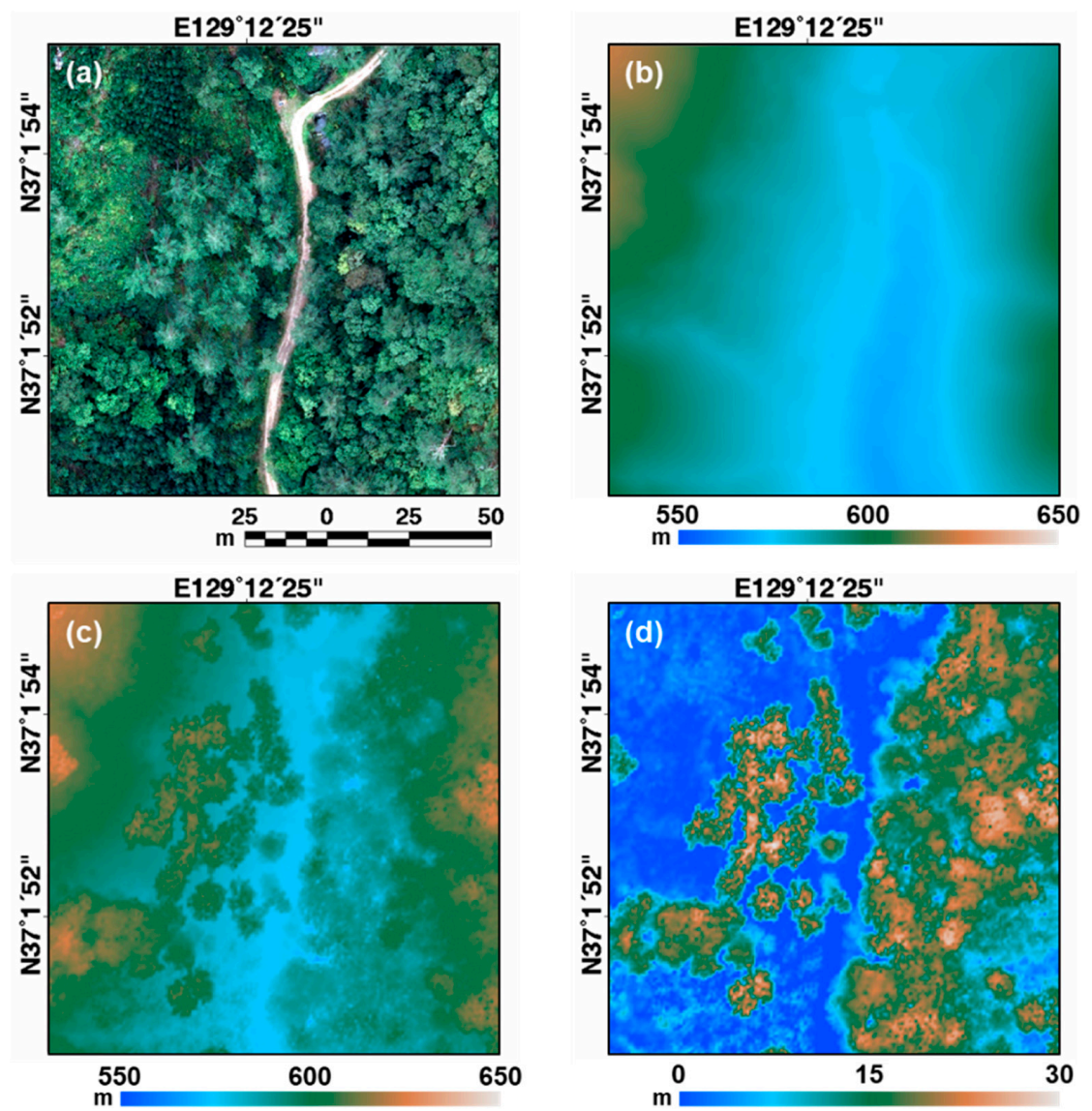

Figure 4. Pre-processing results of (a) aerial image taken in 2016, (b) raster-based digital terrain model, (c) digital surface model, and (d) raster canopy height map of the zoomed-in area of point no. 3 in Figure 1b.

\subsection{Voxel-Based Tree Point Density Mapping}

The voxel-based tree point density maps (Figure 5) provided vertical profile patterns which show tree height and forest vertical structure information. Instead of measuring the heights of individual trees in this study, we used the relative differences of LiDAR point clouds according to height to estimate vertical structure. Figure 5a shows the height of the LiDAR point, i.e., the difference between the $\mathrm{Z}$ elevation of the LiDAR point and elevation of the raster DTM. The calibrated LiDAR point cloud showed height information for $30 \mathrm{~m}$ 
by expressing the distribution of the tree crown visually, which was not represented by the raster $\mathrm{CHM}$.
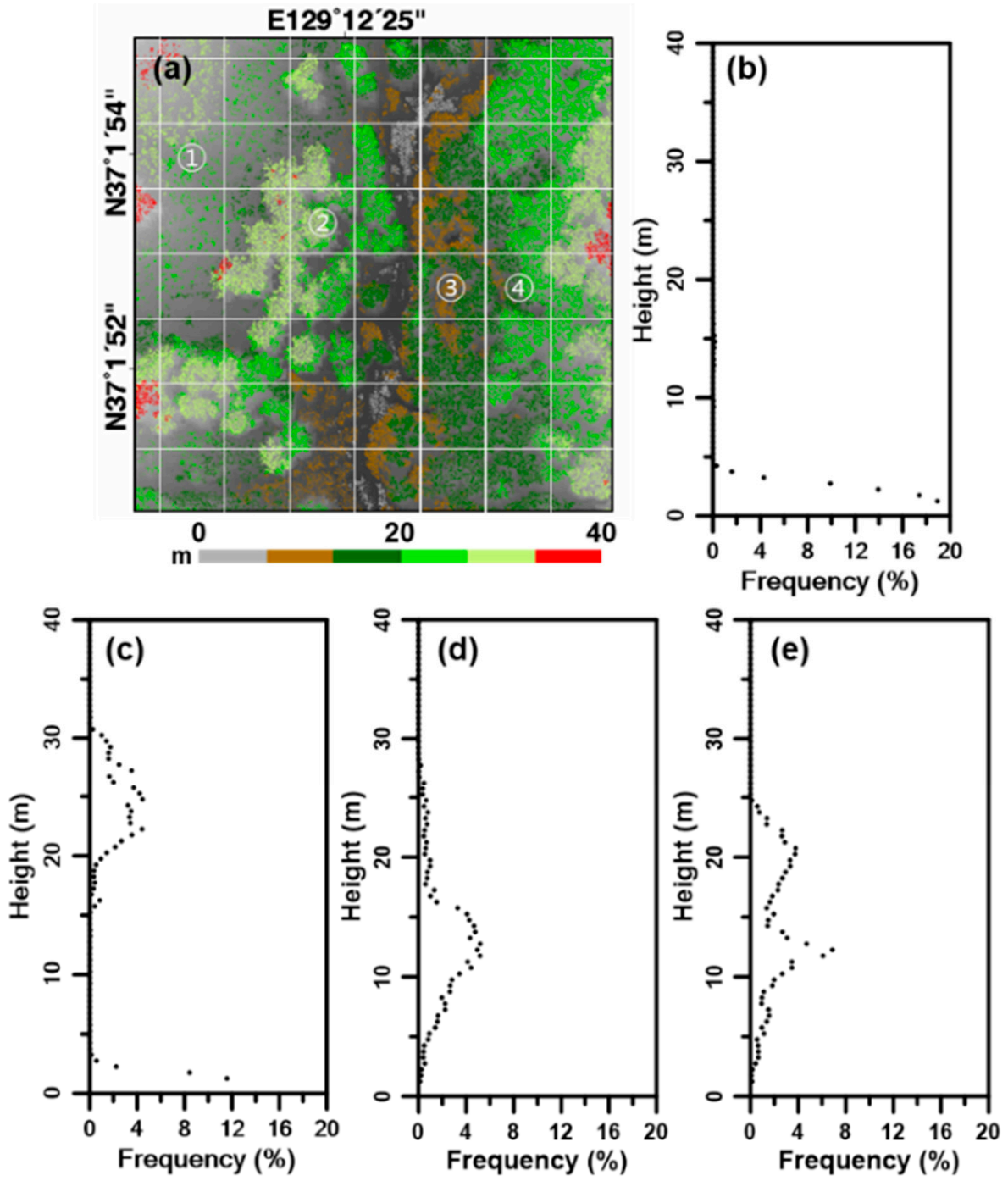

Figure 5. (a) Zoomed-in area of point no. 3 in Figure 1b, showing sample areas. Frequency profiles of LiDAR points at $50 \mathrm{~cm}$ height spacing voxels for (b) sample area no. 1, (c) sample area no. 2, (d) sample area no. 3, (e) sample area no. 4.

The grid of voxels with $20 \mathrm{~m}$ spacing is marked with white lines (Figure 5a). Figure 5b-e shows the respective frequency profiles of LiDAR points at $50 \mathrm{~cm}$ height interval voxels for sample areas 1-4 (indicated in Figure 5a). The forest in sample area 1 mostly had heights of $<5 \mathrm{~m}$ and represented $>70 \%$ of the LiDAR points (Figure $5 \mathrm{~b}$ ). Hence, it is possible to infer that the vertical structure of the selected sample area was composed of a one-storied forest with shrubs that are $\sim 5 \mathrm{~m}$ high. Sample area 2 consisted only of trees $\sim 30 \mathrm{~m} \mathrm{high}$, and correspondingly the frequency of LiDAR points in the vertical profile increased in the 20-30 m range (Figure 5c). Sample area 3 showed one peak point; however, the point frequency was concentrated in the 10-15 m height range (Figure $5 \mathrm{~d}$ ), indicating that its vertical structure was different from that in sample area 2, despite both being one-storied. The vertical profile of sample area 4 showed two peaks (10-15 and 15-25 m) unlike other sample areas (Figure 5e). Hence, within this $20 \times 20 \mathrm{~m}$ area, trees of different stories were mixed, indicating a multi-storied forest structure. As such, the study area had various vertical profiles according to the spatial distribution of trees. In summary, each region can be classified as one-storied or multi-storied forest according to the distribution type 
(bimodal or monomodal) of the vertical profile and into different classes according to the height section of the enhanced LiDAR point frequency.

\subsection{Pre-Classification of Forest Vertical Structure}

Using the ISODATA unsupervised classification algorithm, we derived 255 classes from the vertical profile of each cell determined by the voxel grid (Figure 6). The number of classes for unsupervised classification was empirically set to a sufficiently large number of 255 ; since the reclassifying process was expected to give meaning to the pre-classified results through visual interpretation in the next step. Results of the unsupervised classification of the study area are shown in Figure 6a, with various colors indicating different classes, such as roads or meadows. The classification also included a surface aspect for the mountainous areas. According to the aspect of the mountainous region, trees grow differently based on the amount of sunlight they receive. Therefore, the pre-classification results of this study can be judged qualitatively valid. Eight randomly selected vertical profiles of the 255 classes are plotted in Figure 6b. The red line in each graph indicates the frequency average at $50 \mathrm{~cm}$ intervals and can be defined by the vertical structure of each class.

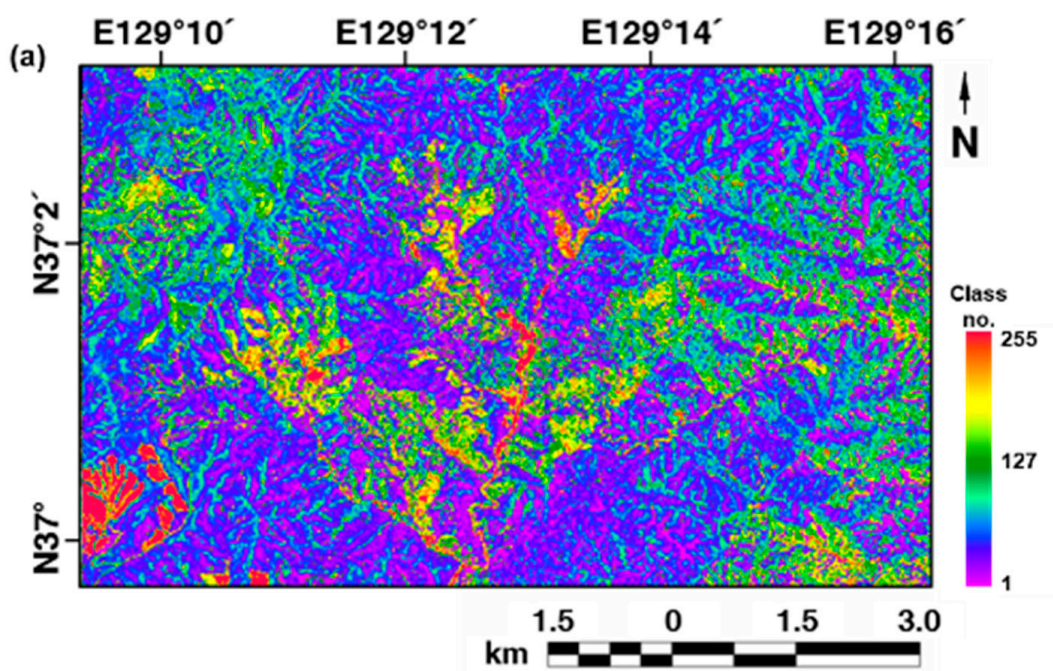

(b)
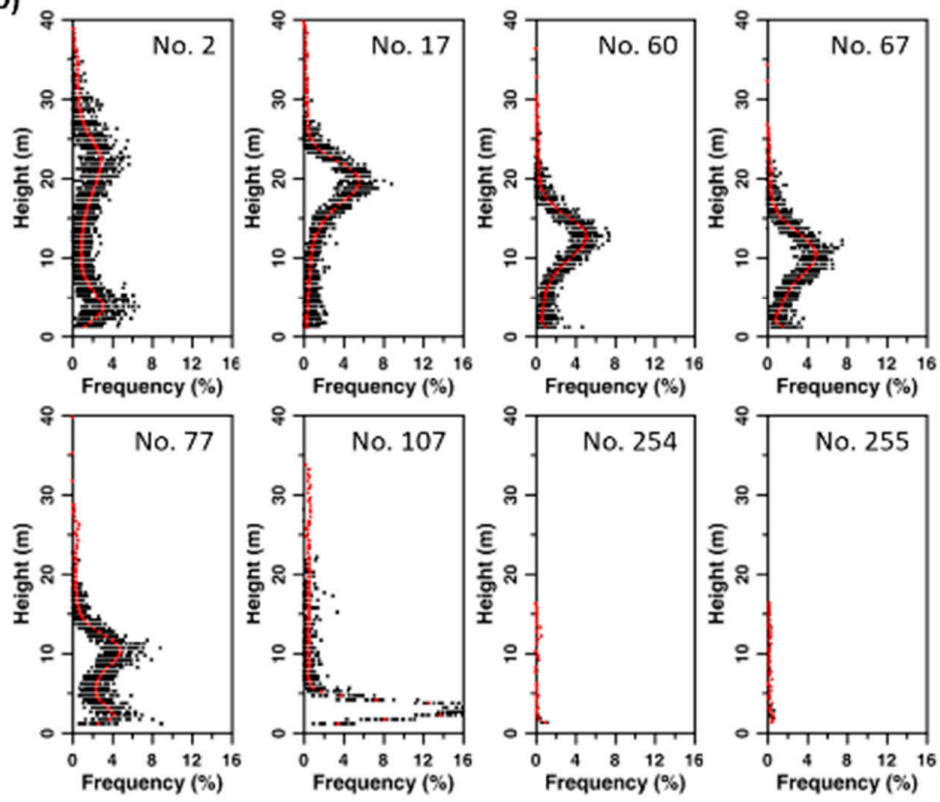

Figure 6. (a) Pre-classification map of forest vertical structure with 255 classes obtained using ISODATA algorithm, and (b) randomly selected eight representative profile patterns among 255 classes. 
The profiles of classes 17,60, and 107 are similar as they are unimodal; however, they differ in height and frequency of their peaks. Classes 2 and 77 are bimodal; however, their heights of the peak point are different. As a result of applying an unsupervised classification algorithm, these samples show that each class has a distinct vertical profile pattern. However, some classes have qualitatively similar profiles. For example, classes 60 and 67 show similar profile patterns. Likewise, profiles for classes 254 and 255 are primarily concentrated at the ground height, showing a very similar vertical structure with little representation above $2 \mathrm{~m}$ height.

In summary, the unsupervised classification algorithm applied in this study was useful for assessing the pattern of vertical forest structure in the study area without prior information. However, because some classes were very similar and had the same properties, there is a limitation in representing the vertical structure of the study area. Therefore, we integrated similar classes from unsupervised classification results by profile pattern analysis. Based on this, the vertical structure was reclassified into seven distinct classes and it was used for the reference data for forest vertical structure pattern, assumed as ground truth.

Details of the seven classes obtained after reclassifying profile patterns of 255 classes are shown in Table 1, along with photographs from the field investigation. We simplified the pre-vertical structure classification into three main types: ground surface, one-storied forest, and multi-storied forest. The single- and multi-storied forest types were subdivided into three. The first criterion for dividing forest types was the number of peak points. Onestoried forest had one peak point, whereas the multi-storied forest had two or more peak points. The ground surface could also be considered as having one peak point; however, it was distinct from the one-storied forest in that it showed a pattern of accelerating frequencies when approaching the surface. In the case of the one-storied forest, further classes were determined based on the height of the peak point, whereas for the multistoried forest, classes were determined based on the frequency of two peak points. Based on the above scheme, we eventually defined seven forest structure classes.

The first forest structure class (class 2) represented shrubland, where the profile showed only one peak point with a high frequency below $5 \mathrm{~m}$ height; this was confirmed from field investigation. The second class (class 3) represented a one-storied, low-height tree forest with a single peak in the height range of 5-15 $\mathrm{m}$. The forest in this class primarily included areas after the reforestation project. The third class (class 4) was also one-storied, with peak point occurring at $>15 \mathrm{~m}$ height; this class primarily included areas where reforestation was done several years ago.

The fourth, fifth, and sixth classes were multi-storied forests, mostly consisting of natural forests composed of broad-leaved trees, conifers, and shrubs that developed over a long period of time. The fourth class (class 5) was a two-storied forest termed as "shrub dominant forest" because it was mainly composed of pine forests on the upper story and shrubs on the lower story. The profile shows that the frequency of the lower peak point was higher than the upper peak. As the upper pine story had acicular leaves, a significant portion of LiDAR points could penetrate to the lower shrubs. The fifth class (class 6) was also two-storied, composed of broad-leaved forest on the upper story and shrubs on the lower story. Unlike the fourth class, since broad-leaved trees in the upper story had large leaves, most of the LiDAR points were reflected by the upper story. Hence, the frequency of the upper peak point was higher than the frequency of the lower story. The final class (class 7) was a mixed forest with no discernible peak points in the profiles. Despite the absence of peak points, it was classified as a multi-storied forest because the trees with various heights were distributed at a similar frequency. The photo from the field investigation shows that, in the area where various trees were mixed, the frequency of the profile changed irregularly and gradually. As described above, the seven classes were suggested through the analysis of 255 classes of vertical profile patterns generated from ISODATA classification and field survey results. 
Table 1. Profile patterns and representative profiles for pre-vertical structure classification of the study area.

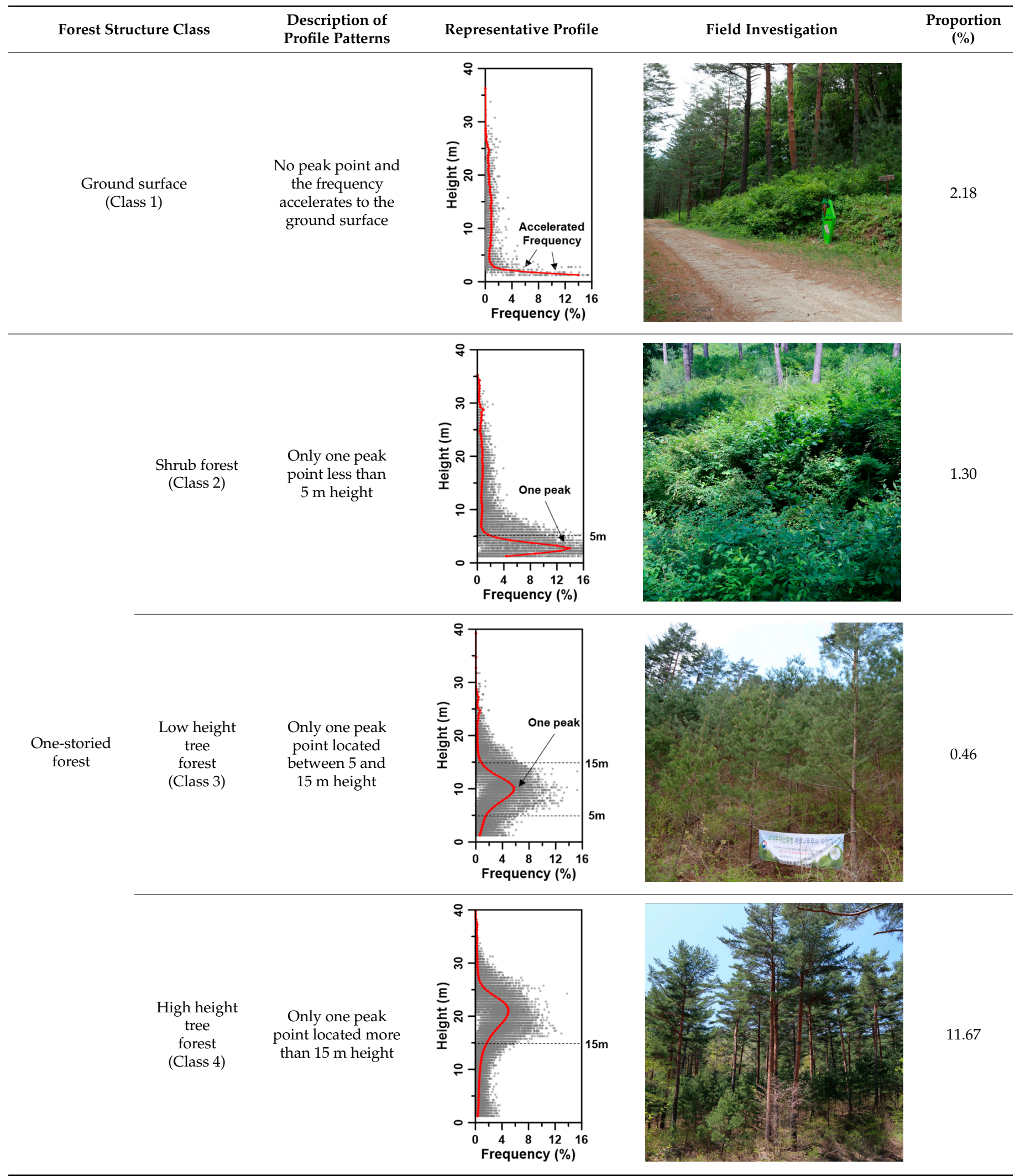


Table 1. Cont

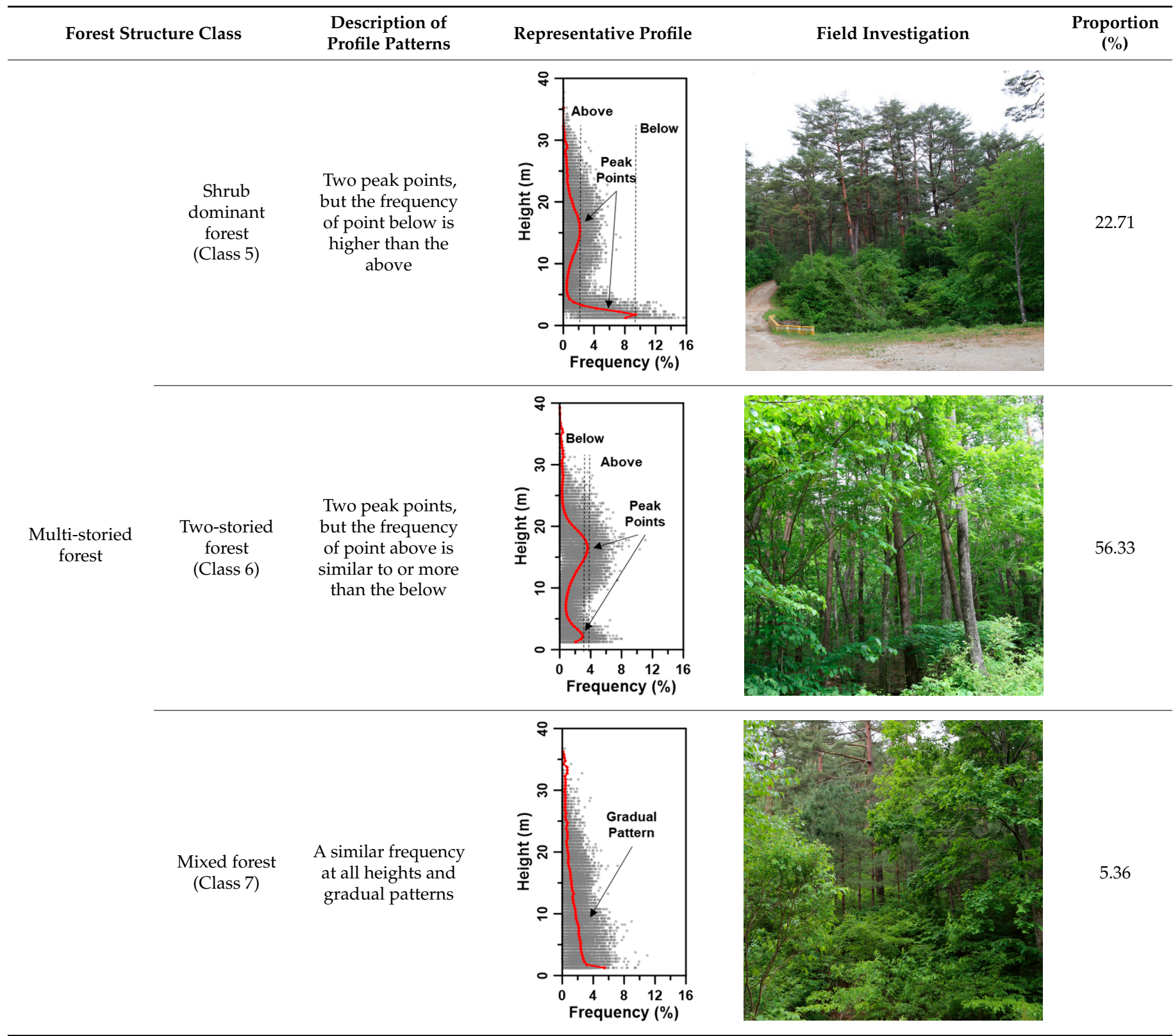

The pre-vertical structure classification map of the study area according to the classification criteria suggested in this study is shown in Figure 7. Classes 1, 4, 5, and 6 occupied most of the study area, indicating that the study area is a natural forest designated as a conservation area for a long time. The area corresponding to class 1 was a hiking trail, and it can be confirmed that there was a one-storied forest with high trees along the trail. Conversely, the areas away from the hiking trail showed a concentrated distribution of classes 5 and 6 . This was confirmed during field investigation; points 1-7 were situated near the hiking trail. This hiking trail had approximately 21,000 visitors in 2019 and was characterized by a variety of vertical structures. Human activities have a variety of effects on forests, such as fragmentation, isolation of forests and human pressure on soils and vegetation [45]. In contrast, field investigation points $8-11$ indicated a general conservation area, where classes 5 and 6 dominated. Thus, it can be inferred that hiking trails and human activities, such as forest management, affected the forests. 

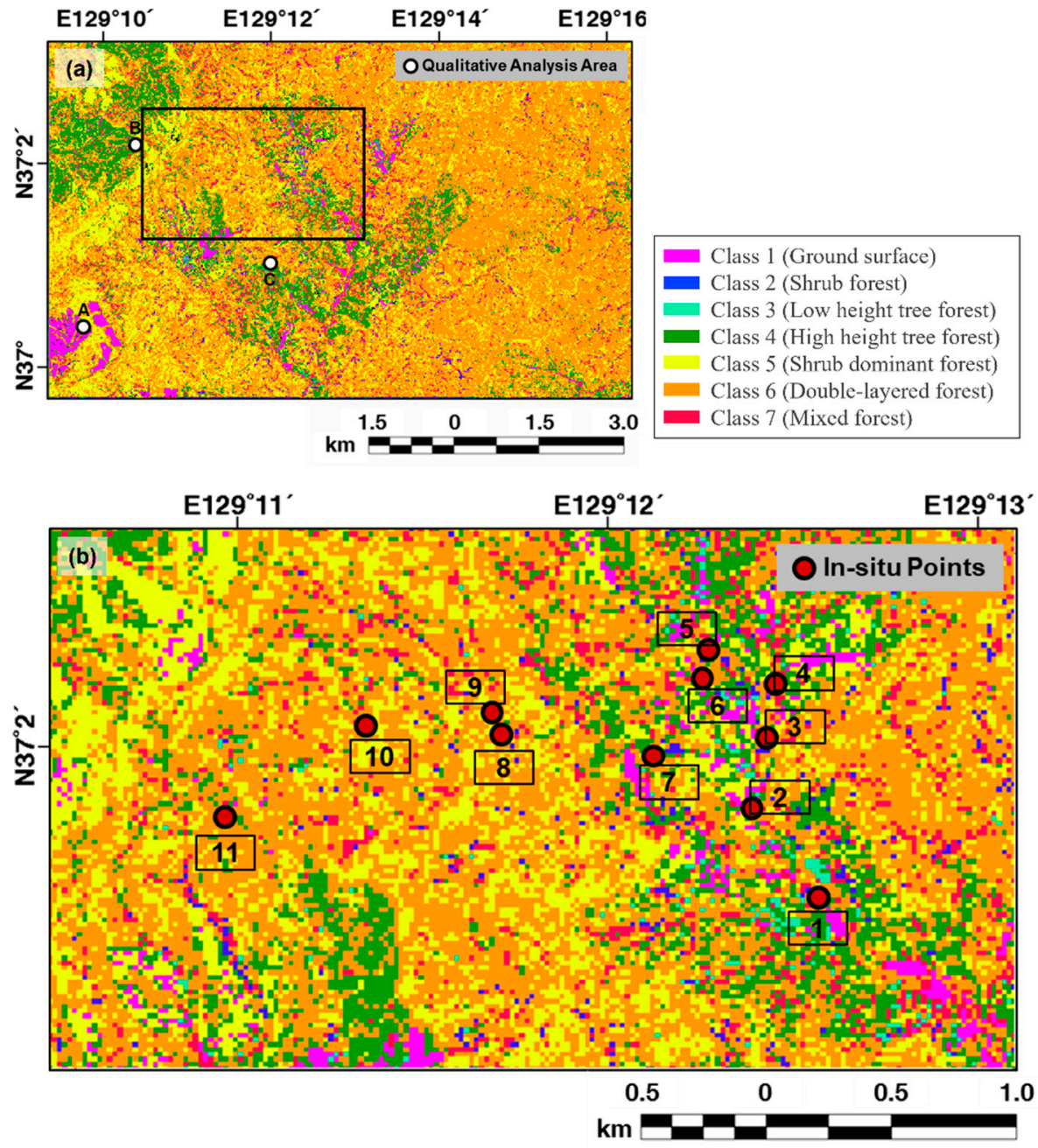

Figure 7. (a) Classification map of forest vertical structure for the study area, and (b) location of 11 in situ points.

For validation, we compared the pre-vertical structure classification map and field investigation results (Table 2). Eight out of the 11 field investigation sites matched well with the classification results, with an estimated classification accuracy of $72.73 \%$. Sites 4 and 7 were classified as high-canopy forest; however, field investigation showed that they were actually two-storied forest with low-height shrubs. This suggests that (1) the LiDAR point in this region had not penetrated to the lower story, or (2) the transmitted LiDAR points likely reached the ground surface but had not been reflected in the classification. However, most of the LiDAR points would have penetrated the upper story since it was mostly composed of needle-leaved pine trees. Therefore, the transmitted LiDAR points were likely to have reached the ground surface and were ignored during the classification process. This area was a steep slope at the edge of a flat hiking trail, and it is possible that the DTM was determined to be lower than it really was, during the interpolation of the DTM; consequently, LiDAR points reaching the surface may have been ignored.

Site 6, classified as a multi-storied structure, was identified as shrub-dominant forest during field investigation. Hence, it can be inferred that the transmission of the LiDAR points could have been affected by the density of the upper pine trees, thereby affecting the peak point frequency and, consequently, the classification result. In the case of in situ investigation, a lack of site investigation results limited the validation process to certain classification groups. However, the area where sampling was conducted is near trails with access permitted within the reserve, since the study area is located in a forest genetic 
resource reserve and is not arbitrarily accessible; a sampling dataset was not used to train or test deep learning models, but rather evaluated the reliability of pre-classified results based on their reliability.

Table 2. Profile patterns and representative profiles for pre-vertical structure classification of the study area.

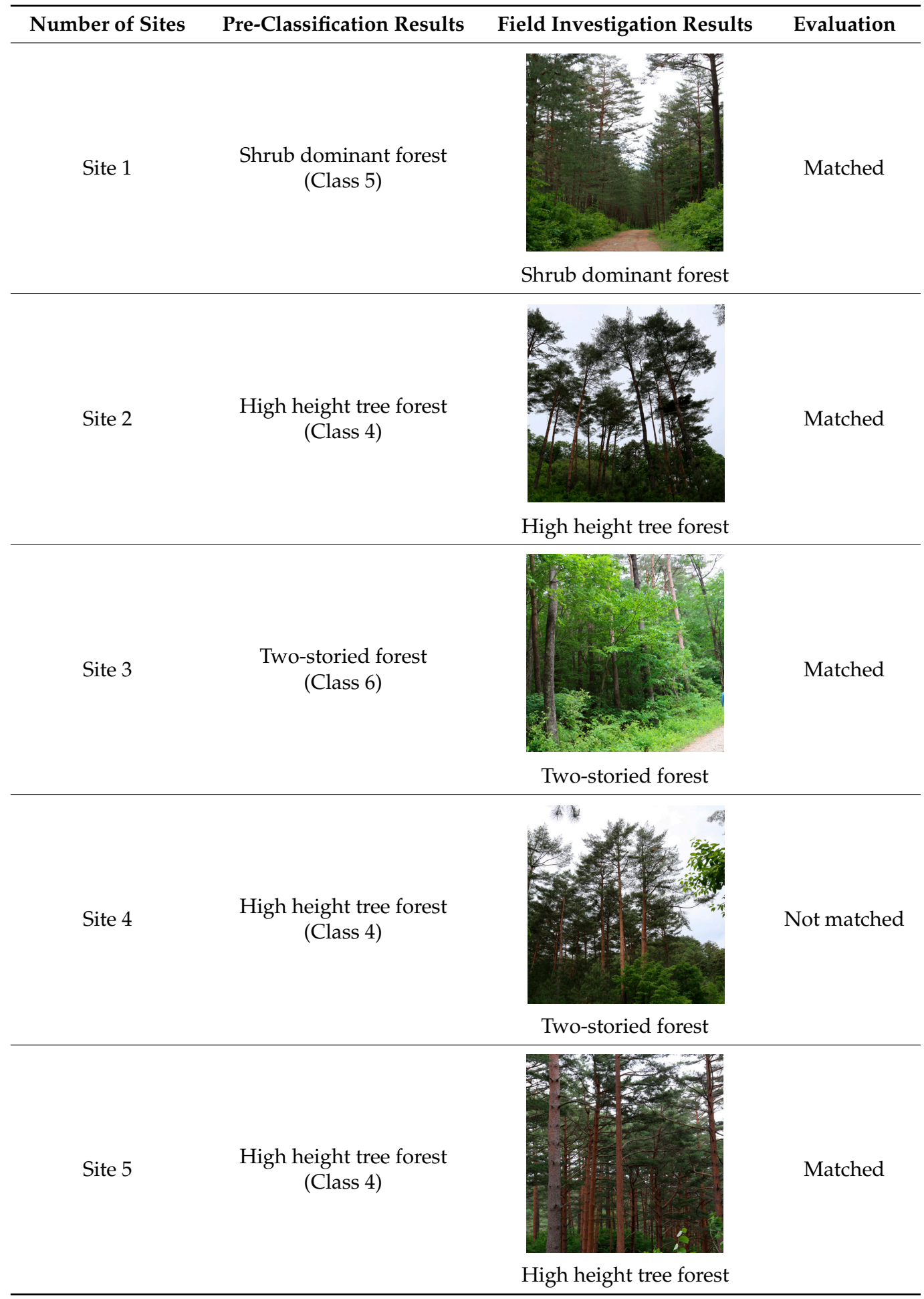


Table 2. Cont.

\begin{tabular}{|c|c|c|c|}
\hline Number of Sites & Pre-Classification Results & Field Investigation Results & Evaluation \\
\hline \multirow[t]{2}{*}{ Site 6} & $\begin{array}{l}\text { Two-storied forest } \\
\text { (Class 6) }\end{array}$ & & Not matched \\
\hline & & Shrub dominant forest & \\
\hline Site 7 & $\begin{array}{l}\text { High height tree forest } \\
\text { (Class } 4)\end{array}$ & & Not matched \\
\hline \multirow[t]{2}{*}{ Site 8} & $\begin{array}{l}\text { Two-storied forest } \\
\text { (Class 6) }\end{array}$ & & Matched \\
\hline & & Two-storied forest & \\
\hline \multirow[t]{2}{*}{ Site 9} & $\begin{array}{l}\text { Shrub dominant forest } \\
\qquad \text { (Class 5) }\end{array}$ & & Matched \\
\hline & & Shrub dominant forest & \\
\hline \multirow[t]{2}{*}{ Site 10} & $\begin{array}{l}\text { Mixed forest } \\
\quad(\text { Class } 7)\end{array}$ & & Matched \\
\hline & & Mixed forest & \\
\hline \multirow[t]{2}{*}{ Site 11} & $\begin{array}{l}\text { High height tree forest } \\
\text { (Class } 4)\end{array}$ & & Matched \\
\hline & & High height tree forest & \\
\hline
\end{tabular}


As shown in Figure 8, classification results in three additional points in Figure 7a were compared with aerial photography by qualitative visual analysis. Most of the LiDAR points in Figure 7a,b were concentrated at a height of 0-2 m, implying that the ground surface class was most accurately classified. Figure $8 c, d$, respectively, shows aerial photographs and vertical classification results for areas having small pine trees and broad-leaved trees. Both areas were classified as two-storied forests; pine forests were classified as shrub-dominant forest, whereas broad-leaved forests were classified as two-storied forests, according to the transmittance of LiDAR points. Figure $8 \mathrm{e}, \mathrm{f}$ also shows forests with different species. In this case, the large pine trees were classified as one-storied forest with high trees. Although it is difficult to distinguish between one-storied and multi-storied forest solely using aerial photography, we assumed that the possibility of one-storied forest is very high by analyzing the surface of the forest visible in the photographs.
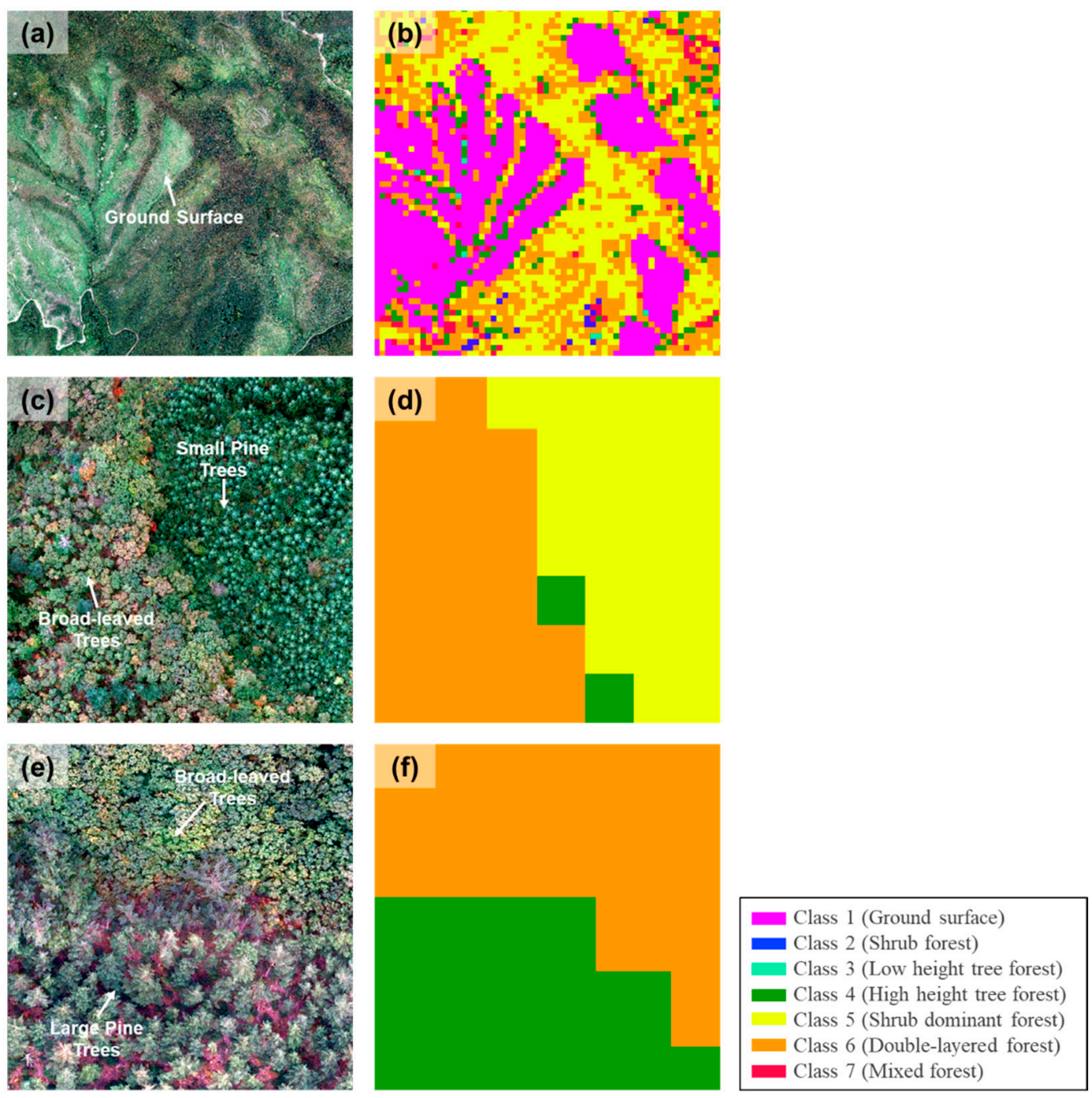

Figure 8. Results of qualitative comparison at three points in Figure 7a with (a-e) aerial photographs with (b-f) classification map with seven vertical structure pattern classes.

\subsection{Classification Map of Forest Vertical Structure}

Based on the pre-classified classes from the forest vertical structure classification map in the previous step, a training and test dataset was extracted. DNN model of previously designed structure was then applied and the final classification map was generated as follows (Figure 9). 


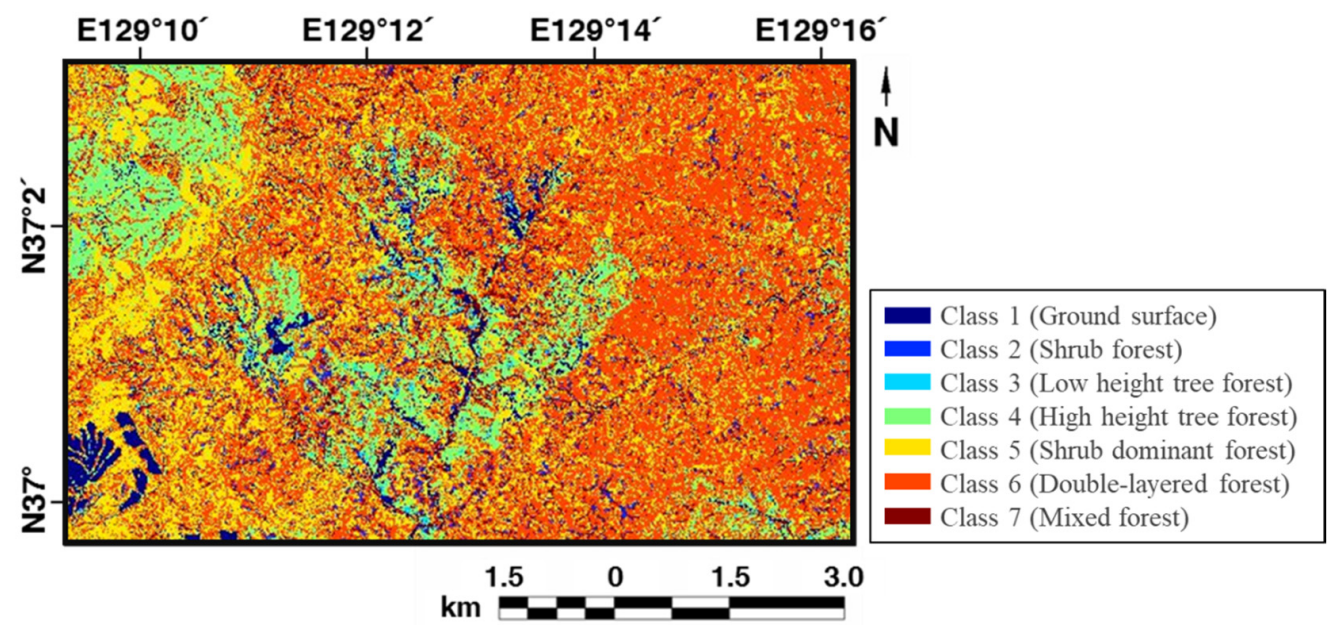

Figure 9. Final forest vertical structure classification map by using deep neural network (DNN).

In order to evaluate the accuracy of each model, a precision-recall curve was created for each classification map based on the pre-classification result. The result of calculating the average precision (AP) representing the area under the precision-recall curve for seven classes is shown in Figure 10. Micro-average was calculated to consider the accuracy of seven classes in each model.

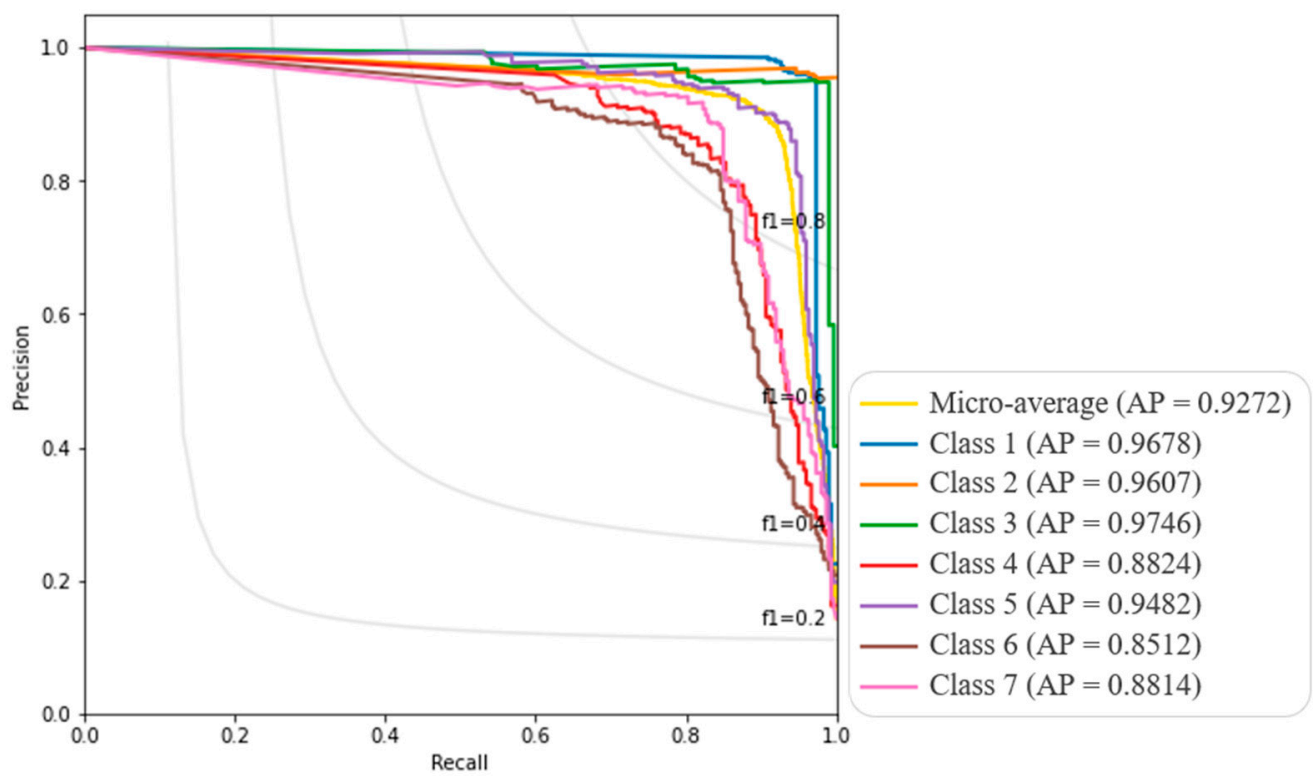

Figure 10. Performance evaluation of deep neural network (DNN) by using average precision (AP).

As a result, it showed high results in every class with micro-averaged overall classes accuracy of 0.9272 . In detail, in the case of classes 1, 2 and 3, which are relatively simple structures, show an accuracy of over $95 \%$; continuously homogeneous areas, such as the mountain trails, shrubs, and grassland, are well-categorized due to their relatively clear patterns. On the other hand, the two-storied forest or mixed forest with a complex vertical structure of the forest showed relatively low accuracy. In the case of two-storied forest, it showed a relatively low accuracy of about $85 \%$; high height tree forest (class 4 ) and mixed forest (class 7) showed an accuracy of about $88 \%$. Even in the case of the class of high height trees, the complexity of the structure increases due to the possibility of the presence of low trees.

Consequently, this is considered to mean that the number of points according to the height within a pixel is important for distinguishing the vertical structure of the forest and 
the complexity of the forest vertical structure affects the classification accuracy. Thus, in the $20 \mathrm{~m}$ class spatial resolution selected in this study, the number of points according to the height within the pixel could be effectively used to classify the vertical structure of the forest.

\section{Conclusions}

This study aimed to classify the vertical structure of the forest genetic resource reserve area in Sogwang-ri, Uljin-gun, Korea. In summary, unsupervised classification was applied to a voxel-based tree point density map generated from a LiDAR point cloud. The preclassification map created in this way was assumed to be real forest vertical structure data and the DNN model was applied for the forest vertical structure classification. The reflection height of the LiDAR point varied according to the spatial distribution of the trees, especially in one-storied and multi-storied structures. We estimated forest vertical structure by analyzing a voxel-based tree point density map and confirmed that one-storied and multi-storied forest types appeared in various methods in the study area. In this way, the significance of this study lies in the fact that it attempted to classify the forest vertical structure solely using LiDAR data.

It is known that large-footprint LiDAR measurements could include canopy height, subcanopy topography, and the vertical distribution of intercepted surfaces from the canopy top to the ground [17]. In this aspect, compared to various studies using LiDAR to estimate the vertical structure of forests $[16,23]$, this study estimated the spatial distribution of vertical structure in the study area based on FW LiDAR data. However, since the results of the study were primarily based on the FW LiDAR data, the accuracy of the results is significantly related to the quality of the data. In general, we concluded that the reliability of the extracted information would be greatly affected by the reliability of the pre-processing steps, such as georegistration and noise removal. In addition, it is important to obtain a large amount of data throughout the target area because it was difficult to obtain LiDAR points that could be matched one-to-one with all trees.

For forest vertical structure mapping, two major issues need to be addressed in the future: (1) three-storied forest could not be detected well with LiDAR data and (2) the validation process with the actual forest vertical structure data. In fact, the vertical structure of the study area includes a large area having a three-storied forest (shrub, understory, and canopy), which is difficult to confirm using the canopy height points. This a likely due to difficulties in distinguishing between the ground surface and the shrub. In the case of the three-storied forest, we assumed that many LiDAR points were reflected before reaching the shrub layer. Nevertheless, this study is significant in the following respects: (1) very few studies have been conducted to classify tree stories using FW LiDAR data with a large number of points, (2) single- and two-storied forest were clearly classified, especially by using DNN, and (3) in-depth information was obtained for the Geumgang Pine Forest, which is designated as a forest genetic resource protection zone.

The results of this study demonstrate that the LiDAR-derived canopy height points can be used as basic data for forest analysis studies. Based on this voxel-based map, it is possible to conduct further investigations such as tree height and crown measurement, biomass estimation, and forest structure analysis with high accuracy over a wider area. In particular, the necessity of field surveys to assess the internal structure of the forest could be overcome by applying the methodology proposed in this paper. Additionally, the proposed method can be used to estimate the forest vertical structure with fairly high accuracy for a large area. Furthermore, the proposed method can also help generate basic data on the characteristics of forest structure, which can be further used to formulate policies for the protection, conservation, and management of forests. 
Author Contributions: Conceptualization, S.L.; data curation, S.-H.P. and E.-S.K.; formal analysis, H.-S.J.; investigation, E.-S.K.; methodology, S.-H.P. and H.-S.J.; resources, E.-S.K.; software, S.-H.P.; supervision, H.-S.J.; validation, S.-H.P. and S.L.; writing-original draft, S.-H.P. and S.L.; writingreview and editing, H.-S.J. and S.L. All authors have read and agreed to the published version of the manuscript.

Funding: This work was supported by the National Research Foundation of Korea funded by the Korea government under Grant NRF-2018M1A3A3A02066008, and it was also conducted at Korea Environment Institute (KEI) with support from project “Development of Technology for Multiple Natural Hazards to Analyze the Casual Relationship between cause of occurrence and damage status and to Predict Spatio-Temporal Damage (2021-027(R))," in the Basic Science Research Program funded by the National Research Foundation of Korea (NRF-2018R1D1A1B07041203). This study was also supported by the National Institute of Forest Science, Republic of Korea (project number FE0100-2019-05).

Institutional Review Board Statement: Not applicable.

Data Availability Statement: The data presented in this study are available on request from the National Institute of Forest Science. The data are not publicly available due to Forest Genetic Resource Reserve policy.

Conflicts of Interest: The authors declare no conflict of interest.

\section{References}

1. Dennison, W.C.; Orth, R.J.; Moore, K.A.; Stevenson, J.C.; Carter, V.; Kollar, S.; Bergstrom, P.W.; Batiuk, R.A. Assessing water quality with submersed aquatic vegetation: Habitat requirements as barometers of Chesapeake Bay health. BioScience 1993, 43, 86-94. [CrossRef]

2. Gardner, T.A.; Barlow, J.; Chazdon, R.; Ewers, R.M.; Harvey, C.A.; Peres, C.A.; Sodhi, N.S. Prospects for tropical forest biodiversity in a human-modified world. Ecol. Lett. 2009, 12, 561-582. [CrossRef] [PubMed]

3. Ruiz-Jaen, M.C.; Mitchell Aide, T. Restoration success: How is it being measured? Restor. Ecol. 2005, 13, 569-577. [CrossRef]

4. Tews, J.; Brose, U.; Grimm, V.; Tielbörger, K.; Wichmann, M.C.; Schwager, M.; Jeltsch, F. Animal species diversity driven by habitat heterogeneity/diversity: The importance of keystone structures. J. Biogeogr. 2004, 31, 79-92. [CrossRef]

5. Saldaña, A.; Parra, M.J.; Flores-Bavestrello, A.; Corcuera, L.J.; Bravo, L.A. Effects of forest successional status on microenvironmental conditions, diversity, and distribution of filmy fern species in a temperate rainforest. Plant Species Biol. 2014, 29, $253-262$. [CrossRef]

6. Dieler, J.; Uhl, E.; Biber, P.; Müller, J.; Rötzer, T.; Pretzsch, H. Effect of forest stand management on species composition, structural diversity, and productivity in the temperate zone of Europe. Eur. J. For. Res. 2017, 136, 739-766. [CrossRef]

7. Garden, J.G.; Mcalpine, C.A.; Possingham, H.P.; Jones, D.N. Habitat structure is more important than vegetation composition for local-level management of native terrestrial reptile and small mammal species living in urban remnants: A case study from Brisbane, Australia. Austral Ecol. 2007, 32, 669-685. [CrossRef]

8. Anderson, H.W.; Hoover, M.D.; Reinhart, K.G. Forests and Water: Effects of Forest Management on Floods, Sedimentation, and Water Supply; Department of Agriculture, Forest Service, Pacific Southwest Forest and Range Experiment Station: Albany, CA, USA, 1976; Volume 18.

9. Bonan, G.B. Forests and climate change: Forcings, feedbacks, and the climate benefits of forests. Science 2008, 320, 1444-1449. [CrossRef] [PubMed]

10. Hoen, H.F.; Solberg, B. Potential and economic efficiency of carbon sequestration in forest biomass through silvicultural management. For. Sci. 1994, 40, 429-451.

11. Gibbs, H.K.; Brown, S.; Niles, J.O.; Foley, J.A. Monitoring and estimating tropical forest carbon stocks: Making REDD a reality. Environ. Res. Lett. 2007, 2, 045023. [CrossRef]

12. Seidel, D.; Fleck, S.; Leuschner, C.; Hammett, T. Review of ground-based methods to measure the distribution of biomass in forest canopies. Ann. For. Sci. 2011, 68, 225-244. [CrossRef]

13. Segura, M.; Kanninen, M. Allometric Models for Tree Volume and Total Aboveground Biomass in a Tropical Humid Forest in Costa Rica 1. Biotropica J. Biol. Conserv. 2005, 37, 2-8.

14. Lu, D.; Chen, Q.; Wang, G.; Liu, L.; Li, G.; Moran, E. A survey of remote sensing-based aboveground biomass estimation methods in forest ecosystems. Int. J. Digit. Earth 2016, 9, 63-105. [CrossRef]

15. Lee, Y.-S.; Lee, S.; Jung, H.-S. Mapping forest vertical structure in Gong-ju, Korea using Sentinel-2 satellite images and artificial neural networks. Appl. Sci. 2020, 10, 1666. [CrossRef]

16. Lee, Y.-S.; Lee, S.; Baek, W.-K.; Jung, H.-S.; Park, S.-H.; Lee, M.-J. Mapping Forest Vertical Structure in Jeju Island from Optical and Radar Satellite Images Using Artificial Neural Network. Remote Sens. 2020, 12, 797. [CrossRef]

17. Dubayah, R.O.; Drake, J.B. Lidar remote sensing for forestry. J. For. 2000, 98, 44-46.

18. Korea Forest Service. Forest Basic Statistics; Korea Forest Service: Daejeon, Korea, 2015. 
19. Sun, J.; Yu, X.; Wang, H.; Jia, G.; Zhao, Y.; Tu, Z.; Deng, W.; Jia, J.; Chen, J. Effects of forest structure on hydrological processes in China. J. Hydrol. 2018, 561, 187-199. [CrossRef]

20. Bergen, K.; Goetz, S.; Dubayah, R.; Henebry, G.; Hunsaker, C.; Imhoff, M.; Nelson, R.; Parker, G.; Radeloff, V. Remote sensing of vegetation 3-D structure for biodiversity and habitat: Review and implications for lidar and radar spaceborne missions. J. Geophys. Res. Biogeosci. 2009, 114. [CrossRef]

21. Wulder, M.A.; White, J.C.; Nelson, R.F.; Næsset, E.; Ørka, H.O.; Coops, N.C.; Hilker, T.; Bater, C.W.; Gobakken, T. Lidar sampling for large-area forest characterization: A review. Remote Sens. Environ. 2012, 121, 196-209. [CrossRef]

22. Wang, Y.; Weinacker, H.; Koch, B. A lidar point cloud based procedure for vertical canopy structure analysis and 3D single tree modelling in forest. Sensors 2008, 8, 3938-3951. [CrossRef] [PubMed]

23. Zimble, D.A.; Evans, D.L.; Carlson, G.C.; Parker, R.C.; Grado, S.C.; Gerard, P.D. Characterizing vertical forest structure using small-footprint airborne LiDAR. Remote Sens. Environ. 2003, 87, 171-182. [CrossRef]

24. Leitold, V.; Keller, M.; Morton, D.C.; Cook, B.D.; Shimabukuro, Y.E. Airborne lidar-based estimates of tropical forest structure in complex terrain: Opportunities and trade-offs for REDD+. Carbon Balance Manag. 2015, 10, 3. [CrossRef]

25. Goodwin, N.R.; Coops, N.C.; Culvenor, D.S. Assessment of forest structure with airborne LiDAR and the effects of platform altitude. Remote Sens. Environ. 2006, 103, 140-152. [CrossRef]

26. Wing, B.M.; Ritchie, M.W.; Boston, K.; Cohen, W.B.; Gitelman, A.; Olsen, M.J. Prediction of understory vegetation cover with airborne lidar in an interior ponderosa pine forest. Remote Sens. Environ. 2012, 124, 730-741. [CrossRef]

27. Heinzel, J.; Koch, B. Exploring full-waveform LiDAR parameters for tree species classification. Int. J. Appl. Earth Obs. Geoinf. 2011, 13, 152-160. [CrossRef]

28. Liao, W.; Van Coillie, F.; Gao, L.; Li, L.; Zhang, B.; Chanussot, J. Deep learning for fusion of APEX hyperspectral and full-waveform LiDAR remote sensing data for tree species mapping. IEEE Access 2018, 6, 68716-68729. [CrossRef]

29. Nie, S.; Wang, C.; Zeng, H.; Xi, X.; Li, G. Above-ground biomass estimation using airborne discrete-return and full-waveform LiDAR data in a coniferous forest. Ecol. Indic. 2017, 78, 221-228. [CrossRef]

30. Lim, K.; Treitz, P.; Wulder, M.; St-Onge, B.; Flood, M. LiDAR remote sensing of forest structure. Prog. Phys. Geogr. 2003, 27, 88-106. [CrossRef]

31. Sumnall, M.J.; Hill, R.A.; Hinsley, S.A. Comparison of small-footprint discrete return and full waveform airborne lidar data for estimating multiple forest variables. Remote Sens. Environ. 2016, 173, 214-223. [CrossRef]

32. Cao, L.; Coops, N.C.; Hermosilla, T.; Innes, J.; Dai, J.; She, G. Using small-footprint discrete and full-waveform airborne LiDAR metrics to estimate total biomass and biomass components in subtropical forests. Remote Sens. 2014, 6, 7110-7135. [CrossRef]

33. Wagner, F.H.; Dalagnol, R.; Tagle Casapia, X.; Streher, A.S.; Phillips, O.L.; Gloor, E.; Aragão, L.E. Regional mapping and spatial distribution analysis of canopy palms in an amazon forest using deep learning and VHR images. Remote Sens. 2020, 12, 2225. [CrossRef]

34. Narine, L.L.; Popescu, S.C.; Malambo, L. Synergy of ICESat-2 and Landsat for mapping forest aboveground biomass with deep learning. Remote Sens. 2019, 11, 1503. [CrossRef]

35. Lv, Q.; Dou, Y.; Niu, X.; Xu, J.; Li, B. Classification of land cover based on deep belief networks using polarimetric RADARSAT-2 data. In Proceedings of the 2014 IEEE Geoscience and Remote Sensing Symposium, Quebec City, QC, Canada, 13-18 July 2014; pp. $4679-4682$.

36. Hamdi, Z.M.; Brandmeier, M.; Straub, C. Forest damage assessment using deep learning on high resolution remote sensing data. Remote Sens. 2019, 11, 1976. [CrossRef]

37. Kim, H.-Y.; Cho, H.-J. Vegetation Composition and Structure of Sogwang-ri Forest Genetic Resources Reserve in Uljin-gun, Korea. Korean J. Environ. Ecol. 2017, 31, 188-201. [CrossRef]

38. Kim, J.; Kim, E.-S.; Lim, J.-H. Topographic and meteorological characteristics of Pinus densiflora dieback areas in Sogwang-ri, Uljin. Korean J. Agric. For. Meteorol. 2017, 19, 10-18. [CrossRef]

39. Gaulton, R.; Malthus, T.J. LiDAR mapping of canopy gaps in continuous cover forests: A comparison of canopy height model and point cloud based techniques. Int. J. Remote Sens. 2010, 31, 1193-1211. [CrossRef]

40. Terrasolid. TerraScan User's Guide; Terrasolid: Helsinki, Finland, 2004.

41. Popescu, S.C.; Zhao, K. A voxel-based lidar method for estimating crown base height for deciduous and pine trees. Remote Sens. Environ. 2008, 112, 767-781. [CrossRef]

42. Creation and Management of Forest Resources Act. 1. Available online: https:/ / elaw.klri.re.kr/kor_service/lawView.do?hseq=51 186\&lang=ENG (accessed on 25 August 2021).

43. Richards, J.A.; Richards, J. Remote Sensing Digital Image Analysis; Springer: Berlin/Heidelberg, Germany, 1999 ; Volume 3.

44. Lillicrap, T.P.; Santoro, A.; Marris, L.; Akerman, C.J.; Hinton, G. Backpropagation and the brain. Nat. Rev. Neurosci. 2020, 21, 335-346. [CrossRef] [PubMed]

45. Referowska-Chodak, E. Pressures and threats to nature related to human activities in European urban and suburban forests. Forests 2019, 10, 765. [CrossRef] 